\title{
Effect of two organic chemical fluids on the mechanical properties of an expansive clay soil
}

\author{
A. R. Estabragh \\ Associate Professor, Faculty of Soil and Water Engineering, University of Tehran, PO \\ BOX 4411 Karaj 31587-77871, Alborz, Iran \\ Correspomding Author: A.R. Estabragh \\ ORCID: 0000-0003-4545-2310 \\ Tel: +982632241119 \\ Fax: +982632226181 \\ Email: raeesi@ut.ac.ir \\ E. Afsari \\ Postgraduate Student, Faculty of Soil and Water Engineering, University of Tehran, PO \\ BOX 4411 Karaj 31587-77871, Alborz, Iran \\ Tel: +982632241119 \\ Fax: +982632226181 \\ Email: afsari.e@ut.ac.ir
}

A. A. Javadi

Professor, Computational Geomechanics Group, Department of Engineering, University of Exeter, Devon, EX4 4QF, UK

Tel: +44 1392723640

Fax: +44 1392217965

Email: $\underline{\text { A.A.javadi@exeter.ac.uk }}$

M. Babalar

Postgraduate Student, Faculty of Soil and Water Engineering, University of Tehran, PO BOX 4411 Karaj 31587-77871,Alborz, Iran

Tel: +98 2632241119

Fax: +98 2632226181

Email: babalar@ut.ac.ir 


\title{
Effect of two organic chemical fluids on the mechanical properties of an expansive clay soil
}

\begin{abstract}
An experimental study was conducted to investigate the effect of two organic chemical fluids (glycerol and acetone) on the mechanical behavior of an expansive clay soil. A number of experimental tests including Atterberg limits, compaction, free swelling, Unconfined Compressive Strength (UCS), CBR (California Bearing Ratio) and one dimensional consolidation (loading and unloading) tests were conducted on samples of the natural soil and soil contaminated with pure glycerol and acetone fluids at different percentages $(10,15$ and $20 \%)$ by weight. The results showed that the effect of pure glycerol on the behavior of the contaminated soil is different from acetone. Glycerol caused reduction of Atterberg limits, free swelling, unconfined compressive strength, CBR and optimum water content and increase in maximum dry unit weight while acetone showed the opposite effects. These variations of the mechanical and physical behavior are a function of the percent of glycerol or acetone. Furthermore, the results of the loading and unloading tests showed that the compression and swelling indices are independent of the type of organic chemical fluids used. Results from SEM (Scanning Electron Microscopy) tests confirmed that the effect of glycerol on the behavior of soil is not the same as acetone.

Key words: Expansive soil, glycerol, acetone, Atterberg limits, free swelling, consolidation
\end{abstract}




\section{Introduction}

Organic chemicals are the foundations of numerous industries such as fuel refining, petrochemical complexes, plastics manufacturing, detergent industry, etc. The improper use of organic chemicals and accidents are sources of contaminated environment. Glycerol is an organic chemical which is usually transported by tank truck, ship, container and drum. Accidents during transportation may lead to contamination of soil and water by glycerol. The source pollution for acetone is mainly leaching from municipal and industrial landfills ([1]) that pollute the soil and water in addition to transportation accidents. Therefore, soil contamination is a general problem often arising from different industrial activities on the site leading, in many cases, to a mixture of contaminants in the soil. Understanding the chemical nature of organic contaminants is important in assessing the routes of exposure and the feasibility and methods of remediation.

The response of soil to the contaminants depends on the type of soil and nature of organic contaminants. The interaction of contaminants with soil can be divided into mechanical and physicochemical interactions. Mechanical interactions usually occur in granular soils while physicochemical interactions occur in cohesive soils. Fang [2] presented an index, so called the sensitivity index, to explain the interaction of soil with contaminants. He defined the range of this index between $0-1$ for different types of soil. The value of sensitivity index for sand and gravel is in the range of 0.01-0.1 and for clay particles between 0.6-0.9. This index shows that the interaction of the contaminant with clay soil is more than granular soil.

Adsorption of contaminants to the soil particles is defined as surficial attachment. Adsorption can be divided into two categories of physical and chemical adsorption. 
Physical adsorption of contaminants occurs as a result of the attraction of contaminants to the surface of clay minerals mainly by van der Waals forces. Chemical adsorption or chemisorption involves the formation of stronger and more permanent bonds of chemical nature (i.e. covalent bonding) with higher energies than physical adsorption. Lagaly et al. [3] described the intercalation condition in the adsorption of organic compounds. They used the term intercalated guest molecules for the organic molecules that penetrate between the interlayer spaces of clay minerals. They stated that these intercalated molecules can be displaced by other suitable molecules. The interlayer cations can be exchanged by various types of organic cations. Yong [4] explained different mechanisms for binding organic chemical matters to the soil.

The structure of clay soil depends on the type and amount of clay and physicochemical properties of the pore fluid [5]. The amount of physicochemical interaction in soil can be explained by the diffuse double layer theory. Reduction or shrinkage of the double layer thickness produces a flocculated structure while an increase in its thickness results in a dispersed structure. The physical and mechanical properties of soil are dependent on its existing structure. These properties are described in the following sections.

Atterberg limits

Foreman and Daniel [6] and Sridaran et al. [7] reported reduction in liquid limit (LL) values due to soil contamination. They explained that this reduction is dependent on the value of dielectric constant of pore fluid; decrease in dielectric constant causes reduction in the value of liquid limit. Also, other researchers found that the values of LL and PL are changed by contamination of soil with organic chemicals (e.g., [7]-[14]).

\section{Compaction and CBR (California Bearing Ratio)}


Compaction and CBR (California Bearing Ratio) characteristics of contaminated soil were studied by [15] and [16]. Al-Sanad et al. [15] carried out compaction tests on Kuwaiti sand contaminated with different percents of crude oil and showed that contamination with crude oil results in increase in the maximum dry unit weight and decrease in optimum water content. They also reported an increase of about $4 \%$ in the CBR for Kuwaiti sand contaminated with crude oil. Singh et al. [16] showed that for CL soil contaminated with used motor oil (U.M.O.) the value of maximum dry unit weight is increased but for $\mathrm{CH}$ soil there is a reduction in maximum dry unit weight and increase in optimum water content.

\section{Swelling and consolidation}

Singh et al. [16] indicated that the swelling characteristics for CL and CH soils increase significantly upon concentration with U.M.O. Consolidation tests were conducted on contaminated soil with different organic fluids ([5], [11], [12], [14], [17]). The results reported from the above research works are inconsistent; some of them found that compression index $\left(C_{c}\right)$ is increased with the introduction of organic fluid while others indicated that it is decreased.

\section{Strength}

Moore and Mitchell [18], Ladd and Martin [19] and Evans et al. [20] studied the shear strength of contaminated sandy soil. They reported that no significant change was observed in shear strength due to the contaminating matter, while Sridharan and Rao [21]-[22] reported an increase in shear strength. Evgin and Dfas [23], Al-Sanad et al. [15], Ghaly [24] and Shin et al. [25] reported reduction in shear strength of sandy soil due to contamination with oil. Rajabi et al. [26] stated that the variations of the shear modulus 
for a sandy soil contaminated with crude oil are dependent on the percent of crude oil. Ratnaweera and Meegoda [27] examined two clay soils with high and low plasticity, contaminated with glycerol. They found from the results of Unconfined Compressive Strength (UCS) tests on fine grained soils that the shear strength is decreased but for low plasticity soil there is no significant change in stress-strain curves. Khosravi et al. [14] showed that the variations of the cohesion intercept and angle of shearing resistance of a cohesive soil contaminated with gas oil are depended on the percentage of gas oil. Estabragh et al. [28] studied the mechanical behavior of a clay soil contaminated with glycerol and ethanol through triaxial tests. They concluded that the angle of shearing resistance is increased with increasing the percent of contaminating matter and is also dependent on the type of contaminating substance. The effect of Mono Ethylene Glycol (MEG) on properties of a clay soil was studied by Estabragh et al. [29] through Unconfined Compressive Strength (UCS) tests. They found the final strength of soil sample is decreased with increasing the percent of MEG. Ghadyani et al. [30] examined the effect of gasoil and kerosene as contaminated matters on the mechanical behavior of two different clay soils. They reported that the behavior of the soil is changed and the amount of change for a specific soil is dependent on the type of contaminating matter.

The term structure is used to describe the geometrical arrangement of different particles within a soil mass. Clay soils have two structures namely micro- and macro-structures. Significant information about the structure of soil can be obtained with advent of scanning electron microscopy (SEM). SEM is now widely used for describe different types of soil behavior ([31]). Researchers use SEM to observe the microstructure of soils under different conditions and to describe their observed behavior (e.g., [12], [32]-[34]). 
In construction projects where the local soil may be contaminated with pollutant products, transportation of suitable soil from other areas may or may not be economical. The use of contaminated soil can be considered in earthworks such as embankments, backfills and roads if there is no pathway for leaching of contaminants to underground water or if the contaminants pose no risk to the public and the environment ([29]). Storage tanks of oil production may be used underground or above ground and in both cases, they are usually founded on natural soil. There is usually the risk of leakage of oil products from storage tanks to natural soil. Therefore, for design and construction of buildings and ensuring their safety, it is necessary to understand the behavior of contaminated soils. The information about the settlement and strength of the soil is important in design and safety analysis.

Review of the literature shows that there has been limited research on behavior of cohesive contaminated soil with high plasticity. On the other hand, it has been shown that chemical solutions at low concentrations have a greater effect on the behavior of clay soils with high plasticity than higher concentrations (e.g., [35] and [36]). In majority of swelling and compression tests on contaminated soils the flooding fluid was the same as the pore fluid of the used sample. Considering the above and to improve the current understanding of the behavior of cohesive contaminated soils, this work was focused on studying the behavior of a contaminated clay soil with high plasticity. Samples of contaminated soil were prepared for different tests with pure contaminating matter at different weight percentages. Distilled water was used for flooding the samples for swelling and consolidation tests.

\section{Materials}


Soil, glycerol and acetone (organic fluids) were used as the basic materials to make the contaminated soil samples. The physical and mechanical characteristics of these materials are as follows.

\section{Soil}

The soil used in this experimental work was a clay and was obtained from around the Karaj city which is located $20 \mathrm{~km}$ west of Tehran (Capital of Iran) at foothills of Alborz Mountains. This city was built on a wide plain with a gentle slope. One of the campuses of Tehran University is in this city. The soil that was used in this work was obtained from Savejbologh plain in west of Karaj at depth of 1.5-3 m. The soil was first ground into powder and then used to prepare the samples. It was composed of $26 \%$ sand, $48.6 \%$ silt and $25.4 \%$ clay. It had a liquid limit of $81.0 \%$ and plasticity index of $53.0 \%$. The optimum water content in standard compaction test was $20.0 \%$ corresponding to maximum dry unit weight of $16.5 \mathrm{kN} / \mathrm{m}^{3}$. The specific gravity of solids $\left(\mathrm{G}_{\mathrm{s}}\right)$ was 2.75 . According to the Unified Soil Classification System (USCS), the soil can be classified as clay with high plasticity $(\mathrm{CH})$. XRD (X-ray diffraction) tests were conducted on samples of the soil. Based on the XRD tests, the minerals of soil were quartz, calcite, feldspar (Na, $\mathrm{Ca}$ ), feldspar $(\mathrm{K})$ and clay minerals. The clay minerals of the soil were Illite and Montmorillonite.

The value of free swelling for the soil was $20.7 \%$ and it can be classified as highly expansive soil (according to the classification system in [37]). The physico chemical properties of the soil are shown in Table 1.

\section{Glycerol and Acetone}


Glycerol and acetone were used as the chemical organic contaminants in the pore fluid. Glycerol (propane-1,2,3-triol) is an oxygenated organic compound with boiling point of $290^{\circ} \mathrm{C}$, viscosity of $1.412 \mathrm{~Pa}$.s and dielectric of 42.5 . Acetone is produced from oxidation of alcohol. The boiling point and viscosity of acetone are $56^{\circ} \mathrm{C}$ and $0.0003 \mathrm{~Pa} . \mathrm{s}$ respectively. It has dielectric constant equal to 20.7. Glycerol and acetone are miscible with water. They can enter the soil in different ways and influence on the properties of the soil. However, their properties, particularly dielectric constant, are different from each other. Therefore, they are chosen as contaminating substance in this work.

\section{Sample preparation}

For preparing contaminated soil samples, the desired air dry mass of the soil with water content of $7 \%$ was selected (about $6 \mathrm{~kg}$ ). The amount of glycerol or acetone was calculated as a percentage of the weight of the air dry soil. The percentages that were used in this work were 10,15 and $20 \%$. The chemical fluid was then sprayed on the predetermined mass of soil and manually mixed. The mixing was done in a covered tray in order to prevent from evaporation of the chemical fluid and to obtain a homogenous mixture. The mixture was kept in a plastic bag for 7 days so that the chemical fluid in the soil could distribute evenly throughout the mass of soil and react with the soil ([5]). Atterberg limits, compaction and CBR tests were then performed on the prepared contaminated soil. Soil samples prepared with specific dimensions were needed for free swelling, unconfined compression and consolidation tests. Static compaction was used to prepare the samples for these tests. Compaction was done in special moulds by applying a static pressure, using a loading machine. The dimensions of the mould that was used for preparing the samples for free swelling and consolidation tests were exactly the same as 
the ring of the oedometer with detachable collars at both ends. The dimensions of the mould used for preparing the samples for unconfined compression tests were $50 \mathrm{~mm}$ diameter and $100 \mathrm{~mm}$ length with detachable collars at both ends. Samples were prepared by static compaction of the natural and contaminated soils in each of the moulds in three layers. Before static compaction, the water content of the natural or contaminated soil was increased to optimum water content due to the corresponding compaction curve. Each layer was compacted to a predefined vertical pressure at a fixed displacement rate of $1.5 \mathrm{~mm} / \mathrm{min}$ until the corresponding maximum dry unit weight due to compaction curve was achieved. All samples were compacted in an identical fashion in order to provide the same initial fabric in the samples.

\section{Testing program}

The laboratory tests were conducted on the natural and contaminated soil samples according to the ASTM (American Society for Testing and Materials) standards. The conducted tests were Atterberg limits ([38]), compaction ([39]), free swelling ([40]), CBR (California Bearing Ratio [41]), unconfined compressive strength (UCS, [42]) and consolidation tests ([43]). The free swelling tests were continued until the swelling reached a constant value. The percent of swell $(s)$ is defined as $\left(\Delta h / h_{i}\right) * 100$, where $h_{\mathrm{i}}$ is the initial thickness of sample and $\Delta h$ is the increase in thickness at a given time. The swell potential is defined as the maximum swell that the sample can achieve. For the unconfined compression tests the rate of loading was chosen as $1 \mathrm{~mm} / \mathrm{min}$ as used by [44]. The loading was continued until failure of sample was achieved while the value of load was recorded continuously. Each of the above tests was repeated three times and the average results were presented as the final results. 
Scanning electron microscopy (SEM) tests were performed on the samples in order to observe the microstructure of the samples in different conditions (uncontaminated, and contaminated with glycerol or acetone). The samples were prepared at the optimum water content and maximum dry unit weight, in small disk shape pieces of $1 \mathrm{~cm}^{3}$ volume (as used by [32] and [45]) and scanned under SEM.

\section{Results}

Table 2 shows the variations of Atterberg limits including LL, PL and PI (plasticity index) for the natural soil and the soil contaminated with different percents of glycerol or acetone. As shown in this table, the values of LL and PI for natural soil are 80.0 and $54.0 \%$. The results (Table 1) show that the values of LL are increased but there is reduction in the values of PI due to the contamination of the soil with glycerol and acetone. The variations of Atterberg limits due to these chemical fluids are a function of the percentage of glycerol or acetone in the soil.

The variations of compaction parameters (maximum dry unit weight and optimum water content) along with air voids lines are shown in Fig.1 and Table 2 for different percentages of glycerol and acetone. As shown in this figure, adding glycerol to natural soil moves the compaction curve to the left and upwards of the natural compaction curve, i.e., causes increase in dry unit weight and decrease in optimum water content. Adding acetone causes the compaction curves to move right and downwards of the natural compaction curve. This causes reduction in maximum dry unit weight and increase in optimum water content. It can be concluded that the effect of glycerol and acetone on compaction characteristics of soil are opposite to one another, similar to the variations of Atterberg limits. 
The results of the swell tests for the natural soil and soil contaminated with different percentages of glycerol and acetone are shown in Fig.2. As shown in this figure, the free swelling curves for different percentages of glycerol are located under the free swelling curve of the natural soil while the curves for the soil with acetone are above that for the natural soil. The order of the locations of these curves is dependent on the percent of the chemical fluid. The amount of swelling for contaminated soil with glycerol and acetone is less and more than that of the natural soil respectively. It can be resulted that these two chemical fluids also have different effects on the potential of swelling.

The results of the unconfined compressive strength (UCS) tests are shown in Fig.3 for the natural soil and the soil contaminated with different percentages of glycerol and acetone. As shown in this figure, the stress-strain curves of the contaminated soils are located below that of the natural soil and the order of them is dependent on the percent of the contaminant. The higher the percentage of contamination, the lower is the location of the stress-strain curves. The results show that adding glycerol or acetone causes reduction in the strength and the amount of reduction in the strength of the samples contaminated with glycerol is more than acetone. There is a significant reduction in strength due to both contaminating fluids.

Fig.4 shows the results of CBR tests for the natural soil and the soil contaminated with different percentages of glycerol or acetone. As shown in this figure the trend of variation of CBR curves is similar to the stress-strain curves in unconfined compression tests.

The results of the one-dimensional consolidation tests including loading and unloading are shown of Figs.5 and 6 in the $e: \ln p^{\prime}$ space ( $e=$ void ratio and $p^{\prime}=$ applied pressure) for the samples contaminated with different percents of glycerol and acetone. The loading 
was continued until the virgin line was achieved and then unloading was conducted. Comparing the results in Figs.5 and 6 shows that the consolidation curves for the soil contaminated with different percents of glycerol are below the natural soil but those for different percents of acetone are located above the consolidation curve of the natural soil. It is resulted that the samples contaminated with acetone are more compressible than those contaminated with glycerol. The order of these curves in the space of $e: \ln p^{\prime}$ is a function of the percent of glycerol or acetone. The compression index $\left(C_{c}\right.$, slope of virgin line) and swelling index $\left(C_{s}\right.$, slope of unloading line) were calculated for the natural soil and the soil contaminated with different percents of glycerol or acetone. The results show that the values of $C_{c}$ and $C_{s}$ for the natural soil are 0.7 and 0.02 respectively. The values of $C_{c}$ and $C_{s}$ for the soils contaminated with different percents of glycerol or acetone are nearly 0.46 and 0.02 . It is resulted that the virgin and swelling lines are nearly parallel with each other for both contaminated fluids.

The pre-consolidation pressure was also calculated for the natural soil and the soil contaminated with different percents of acetone or glycerol. The value of preconsolidation pressure for the natural soil and the soil contaminated with glycerol was 45 $\mathrm{kPa}$ and this value was $91 \mathrm{kPa}$ for the soil contaminated with acetone.

Figs.7a, b and c show the results of the SEM tests for the natural soil and the soil contaminated with glycerol and acetone. As shown in these figures the structure of soil contaminated with these materials is not the same and is different from the natural soil.

\section{Discussion}

Glycerol and acetone were used as contaminating compounds in this work. Glycerol is a kind of alcohol. Alcohols are hydroxyl alkyl compounds with a carbon atom bonded to 
the hydroxyl group. Alcohols act as acids when they lose their $\mathrm{OH}$ proton and act as bases when their oxygen atom accepts a proton ([4]). Acetone is resulted from oxidation of the second type of alcohols. In this group of organic chemicals there is carbon-oxygen in double bond condition. In this case the $\mathrm{C}=\mathrm{O}$ bonds are polarized due to the high electronegativity of the oxygen $(\mathrm{O})$ relative to the carbon $(\mathrm{C})$. Contamination of the soil with glycerol or acetone causes these chemical compounds to penetrate between the layers of clay minerals, a process that is called intercalation ([3]). Intercalated guest molecules can be displaced by other suitable molecules. The micrographs of the natural soil and contaminated soils with $15 \%$ glycerol and acetone are shown in Fig.7. As shown in Fig.7a the natural soil has a flocculated structure but the degree of flocculation is increased when the soil is contaminated with glycerol (Fig.7b). By penetrating between the layers of particles, glycerol causes pasting of particles to each other and formation of coarse particles in comparison with natural soil. Fig.7c shows a micrograph of soil contaminated with acetone. As shown in this figure, penetration of the acetone between the layers of clay changes the particles to a lamellar form with large pores between them. It is seen that the effects of glycerol and acetone on the structure of soil are not the same and this leads to different behaviors in the two contaminated soils.

The results of Atterberg limits for the soil contaminated with glycerol show reduction in the values of LL and PL (Table 2) and this reduction is increased with increasing the percent of glycerol. These results are consistent with the results that were reported by [12], [14] and [46].

The results of the compaction tests (Table 2) show increase in the maximum dry unit weight and decrease in optimum water content. The final value of free swelling (potential 
of swelling) (Table 2) shows a trend similar to Atterberg limits for the soil contaminated with glycerol. Comparing between the results of the soils contaminated with glycerol and acetone shows that the trend of these variations for acetone is in opposite direction of glycerol. This can be explained by the diffuse double layer theory that was proposed by [47] and [48]. In this theory, a thin layer of water around the clay particles is known as diffuse double layer (DDL). Reduction in the thickness of this layer leads to the flocculation of the soil particles. The thickness of this layer is proportional to a number factor such as the square root of the dielectric constant ([49]). Therefore, for organic fluids with lower dielectric constant than water, the thickness of DDL around clay particles is reduced and this leads to flocculated structure of soil mass. The dielectric constant of glycerol is 42.5 , nearly half of that of water. This causes a reduction in the thickness of DDL that leads to the formation of a flocculated structure. A higher percent of glycerol increases the degree of flocculation. By formation of the flocculated structure the specific surface of particles is reduced and the capacity of adsorbed water is decreased. These changes result in reduction in the Atterberg limits, swelling potential and optimum water content and increase in the maximum dry unit weight.

It is expected that acetone would increase the degree of flocculation of soil structure more than glycerol because its dielectric constant is 20.7 , nearly half of glycerol (42.5). In Fig.7c the micrograph of the soil contaminated with acetone shows the particles are lamellar beside each other with relatively larger space between them in comparison with the soil contaminated with glycerol (Fig.7b). Therefore, for the soil contaminated with acetone, the results of the tests (Atterberg limits, compaction parameters and free 
swelling) cannot be explained by the diffused double layer theory. The chemical formula of acetone is:

$\mathrm{CH}_{3}-\mathrm{CO}-\mathrm{CH}_{3}$

According to this formula there is a double bond between oxygen and carbon. This bonding increases the density of electron from carbon to oxygen and it leads a dipole condition with the oxygen having negative charge and carbon with positive charge ([4] and [50]). On the other hand acetone can produce two molecules of acid by oxidation action as:

\section{$\mathrm{CH}_{3}-\mathrm{CO}-\mathrm{CH}_{3}+1.5 \mathrm{O}_{2}=\mathrm{CH}_{3}-\mathrm{COOH}+\mathrm{HCOOH}$}

Therefore, acetone can break the bond between the particles of soil and change them to smaller particles. It was indicated that by oxidation action, acetone can produce two molecules of acid. Therefore, by this action the $\mathrm{pH}$ of the pore fluid solution is decreased and it is changed to acidic condition. Tremblay et al. ([51]) stated that the $\mathrm{pH}$ of pore fluid is important when its values are lower than nine because the hardening matters between particles are dissolved and particles change to finer particles. Therefore, the change the pore fluid chemistry may affect the chemical composition of clays by means of exchangeable cations that influence the properties of clay soil. Chartres et al. [52] carried out XRD tests on soil samples with acetone and concluded that the particles of soil can be changed to smaller particles by the existing acetone in the pores of soil. This increases the specific surface and capacity of absorbed water and hence increases the Atterberg limits and free swelling and changes in compaction characteristics (maximum dry unit weight and optimum water content). 
Table 3 shows the final strength and the percent of CBR for the natural soil and the soil contaminated with different percents of glycerol or acetone. As shown in this table, there is reduction in the final strength and CBR values of the soil due the addition of glycerol or acetone but the reduction due to glycerol is more than acetone. These finding are not in agreement with the results that were presented by [18] and [22] but they are consistent with the results that were published by [27]. It is expected that by increasing the degree of flocculation (due to the lower values of dielectric constants) the strength and CBR values are increased but the results show the opposite trend to this assumption. Ratnaweera and Meegoda [27] suggested that the higher viscosity of contaminant compound in the pore fluid can facilitate displacement of particles. The viscosity of glycerol is $1.412 \mathrm{~Pa}$.s that is more than that of water. Therefore, the presence of glycerol between the particles facilitates the displacement of particles due to loading, leading to reduction of strength. The results in Table 3 show that although the viscosity of acetone is nearly the same as water, but the strength and CBR values of soil contaminated with acetone are less than the natural soil. This can be attributed to the different structures of the natural and contaminated soils. As shown in Fig.7c, the structure of the contaminated soil is composed of finer particles than the natural soil with lamellar form that are nearly parallel with relatively large space between the set particles. This leads to reduction of friction between particles and leads to compressibility of the soil mass. Therefore, the final strength and CBR values of the soil with acetone as pore fluid are less than the natural soil.

As shown in Figs.5 and 6 the consolidation curves due to acetone are located above the natural soil but for glycerol they follow the opposite trend. This is due to the structure 
that the soil samples have gained after contamination. The compression and swelling indices of the contaminated soil (Table 3) are nearly same for both contaminated compounds and also independent from the percent of contamination. These results are not consistent with results that were reported by [5], [11]-[14] who showed that the compression index is not constant and its variation is a function of the type and percentage of contamination. These differences can be attributed to the inundating fluid that was used during consolidation. They used the same fluid for inundating the samples as the pore water but in this work drinking water was used for inundating samples.

The samples prepared for the consolidation tests were in unsaturated state. They have two components of suction, namely matric suction $(S)$ and osmotic suction $(\pi)$. The matric suction component is related to the air-water interface (or surface tension) giving rise to the capillary phenomenon. The variation of matric suction for a specific soil is related to its water content. The osmotic suction component is related to the dissolved solutes in bulk water which is defined as the "free water". When the sample is inundated with drinking water, matric suction is dissipated on saturation of voids by the adsorbed water. The sample may experience osmotic flow into the soil in response to the chemical concentration gradient between the pore fluid and reservoir. Therefore the flow of water in the soil mass due to matric and osmotic suction, besides destroying capillary bonds, may change the pore fluid quality of sample and increase the volume of the pore fluid of sample. In the osmotic flow, diffusion of chemical matter occurs from the soil sample to the reservoir. In other words, the inundation of contaminated samples with drinking water results in solution of glycerol or acetone in water and migration of water to soil sample due to osmotic suction, changing the behavior of the contaminated soil due to the change 
in soil suction. On complete dissipation of osmotic suction gradient, osmotic suction of the reservoir and pore fluid becomes the same.

This study shows that higher concentration of organic matter produces greater changes in the behavior of the soil. In addition, at the same concentration, the effect of glycerol and acetone on properties of soil may be opposite to each other.

\section{Conclusions}

1- Glycerol and acetone can penetrate between the clay minerals and cause different structure for the soil. Glycerol increases the degree of flocculation and produces coarse particles but acetone changes the particles into lamellar form and nearly parallel, with relatively large space between particles. These differences of structure cause the characteristics of them (such as Atterberg limits, compaction parameters and free swelling) to be different from the natural soil and from each other.

2- The reduction of strength and CBR values of the contaminated soil in comparison with the natural soil is dependent on the kind of behavior of contaminants. Reduction in strength was observed in both soils contaminated with glycerol and acetone. For the soil contaminated with glycerol, this is due to its viscosity. The reduction in strength for the samples contaminated with acetone is due to the dispersed structure and relatively high degree of compressibility of the soil.

3- Inundating the contaminated samples with drinking water caused the osmotic suction between the pore fluid and inundating water. This makes the compression and swelling indices for both contaminated soils to be the same and they are also independent of the percentage of contaminant. 


\section{References}

[1] Brown K.W. and Donnelly K. C., "An estimation of the risk associated with the organic constituents of hazardous and municipal waste landfill leachates", Hazard Waste Hazard Mater, Vol.5, 1988, pp. 1-30.

[2] Fang H.Y., "Introduction to Environmental Geotechnology," CRC Press, Boca Raton, FL.,1997.

[3] Lagaly G., Ogawa M. and Dekany I., "Clay mineral organic interaction”, Handbook of clay science. , Bergaya F, Theng BKG, Lagaly G (eds.)Vol.1, Chapter 7.3, 2006, pp. 309-377.

[4] Yong, R.N, “Geoenvironmental Engineering, Contaminated soils Pollutant fate and Mitigation," CRC Press, 2001.

[5] Meegoda N.J. and Ratnaweera P., "Compressibility of contaminated fine-grained soils”, Geotech. Test. J., Vol. 17, No. 1, 1994, pp. 101-112.

[6] Foreman D.E. and Daniel D.E., "Permeation of compacted clay with organic chemicals”, J. Geotech. Eng., Vol. 112, No. 7, 1986, pp. 669-681.

[7] Sridharan A., El-Shafei A. and Miura N., "A study on the dominating mechanisms and parameters influencing the physical properties of Ariake clay", Lowland Technology International, The official Journal of International Association of Lowland Technology (IALT), Vol. 2, 2000, pp. 55-70.

[8] Sridharan A., Rao S.M. and Murthy N.S., "Liquid limit of montmorillonitics soils", Geotech. Test. J., Vol. 9, 1986, pp.156-159. 
[9] Meegoda N.J. and Rajapakse R.A., "Short-term and long-term permeabilities of contaminated clay”, J. Environ. Eng., Vol. 119, Bo. 4, 1993, pp.725-743.

[10] Soule N.M., Burns S.E., "Effects of organic cation structure on behavior of organobentonities", J. Geotech. Geoenviron. Eng., Vol. 127, No. 4, 2001, pp. 363-370

[11] Singh S.K., Srivastava R.K. and John S., "Settlement characteristics of clayey soils contaminated with petroleum hydrocarbons", Soil Sediment Contam., Vol. 17, No. 3, 2008, pp. 290-300.

[12] Olgun M. and Yildizi M., "Effect of organic fluids on the geotechnical behavior of a highly plastic clayey soil”, Appl. Clay Sci., Vol. 48, 2010, pp. 615-621.

[13] Di Matteo L.D., Bigotti F. and Ricco R., "Compressibility of kaolinitic clay contaminated by ethanol-gasoline blends", J. Geotech. Geoenviron. Eng., Vol.137, No. 9, 2011, pp. 846-849.

[14] Khosravi E., Ghasemzadeh H., Sabour M.R. and Yazdani H., "Geotechnical properties of gas oil-contaminated kaolinite", Eng. Geol., Vol. 166, 2013, pp. 1116.

[15] Al-Sanad H., Eid W.K., and Ismael N. F., "Geotechnical properties of oilcontaminated Kuwaiti Sand", J. Geotech. Geoenviron. Eng. ASCE, Vol.121, No. 2,1995, pp. 407-412.

[16] Singh S.K., Srivastava R.K. and Siby J., "Studies on soil contamination due to used motor oil and its remediation", Can. Geotech. J., Vol. 46, 2009, pp.1077-1083.

[17] Estabragh A.R., Beytolahpour I., Moradi M. and Javadi, A.A. "Consolidation behaviour of two fine-grained soils contaminated by glycerol and ethanol". Eng. Geol., Vol,178, 2014, pp.102-108. 
[18] Moore C.A. and Mitchell J.K., "Electromagnetic forces and soil strength", Géotechnique, Vol. 24, No. 4, 1974, pp. 627-640.

[19] Ladd C.C. and Martin R.T., "The effects of pore fluid on the undrained strength of kaolin", Report to the U.S. Army Crops of Engineers from the Department of Civil Engineering, Massachusetts Institute of Technology Cambridge, Massachusetts, 1967.

[20] Evans J.C., Kugelman I.J. and Fang H.Y., "Organic fluids effects on strength, deformation and permeability of soil-bentonite slurry walls", Proceeding of the seventeenth mid-attlantic industrial waste conference, Pensylvania, USA, 1986, pp. 275-291.

[21] Sridharan A. and Rao G.V., "Mechanism controlling volume change of saturated clays and role of effective stress concept", Géotechnique , Vol.23, 1973, pp. 359371.

[22] Sridharan A. and Rao G., "Shear strength of saturated clays and the role of the effective stress concept", Géotechnique, Vol. 2, 1979, pp. 177-193.

[23] Evgin E. and DFas B.M., "Mechanical behavior of an oil contaminated sand", Proceeding of the Environmental geotechnology (Eds: Usman H, Acar Y), Balkema, Roterdam, 1992, pp. 101-108

[24] Ghaly A.M., "Strength remediation of oil contaminated sands", Proceeding of the seventeenth International Conference on Soils Waste Technology and Management, Philadelphia, 2001.

[25] Shin E.C., Omar M.T., Tahmaz A.A. and Das B.M., "Shear strength and hydraulic conductivity of oil contaminated sand", Proceeding of the fourth International 
Congress on environmental Geotechnics. Rio de Janeiro , Brazil, Balkema publisher, 2002, p.9-13.

[26] Rajabi, H. and Sharifipour, M. " Effect of light crude oil contamination on small strain shear modulus of firoozkooh sand". Eur. J. Environ. Civ. Eng., published on line, 2017.

[27] Ratnaweera P. and Meegoda J.N., "Shear strength and stress-strain behaviour of contaminated soils", Geotech. Test. J., Vol. 29, No. 2, 2006, pp.133-140.

[28] Estabragh A.R., Beytolahpour I., Moradi M. and Javadi, A.A. "Mechanical behavior of a clay soil contaminated with glycerol and ethanol". Eur. J. Environ. Civ. Eng., Vol.20, No. 5, 2016a, pp.503-519.

[29] Estabragh A.R., Khatibi, M. and Javadi, A.A. "Effect of cement on the mechanical behaviour of a soil contaminated with Mono Ethylene Glycol (MEG)". ACI, Mater. J., Vol. 113, No. 6, 2016b, pp.709-717.

[30] Ghadyani M., Hamidi, A. and Hatambeigi, M. "Triaxial shear behavior of oil contaminated clay". Eur. J. Environ. Civ. Eng., published on line, 2016.

[31] Collins K. and Mc Gown A., "The form and function of micro-fabric features in a variety of natural Soil", Geotechnique, Vol. 24, No. 2, 1974, pp. 223-254.

[32] Tremblay H., Duchesne J., Locat J., and Leroueil S., "Influence of the natural of organic compounds on fine soil stabilization with cement", Can. Geotech. J., Vol. 39, No. 3, 2002, pp. 535-546.

[33] Cai y., Shi B., Ng C.W.W. and Tang C.-S., "Effect of poly propylene fiber and lime admixture on engineering properties of clayey soil”, Eng. Geol., Vol. 87, No. 3-4, 2006, pp 230-240. 
[34] Priyanthi M.A., Kalpana S.K. and Driesh R.K., "Insight into role of clay-fluid molecular interactions on permeability and consolidation behavior of $\mathrm{Na}$ Montmorillonite swelling clay", J. Geotech. Geoenviron. Eng., Vol. 138, No, 2, 2012, pp.138-146.

[35] Alawaji H., "Swell and compressibility characteristics of sand bentonite mixtures inundated with liquids" Appl. Clay Sci., Vol.13, No. 3-4,1999, pp. 411430.

[36] Jo H.Y., Katsumi T., Benson C.H. and Edil T.B., "Hydraulic conductivity and swelling of nonprehyrated GCLs permeated with single-species salt solutions", $J$. Geotech. Geoenviron. Eng., Vol. 127, No.7, 2001, pp. 557-567.

[37] McKeen R.G., “ A model for predicting expansive soil behavior”, Proceeding of the $7^{\text {th }}$ International Conference on Expansive Soils, Dalla, USA, 1992, pp1-6.

[38] ASTM D 4318-2005, "Standard test method for Atterber limit." Annual book of ASTM standards, soil and rock, West Conshohocken, PA: American Society for Testing and Materials.

[39] ASTM D698-2012e2, "Standard test method for compaction." Annual book of ASTM standards, soil and rock, West Conshohocken, PA: American Society for Testing and Materials.

[40] ASTM D4546-2014, "Standard test method for free swelling." Annual book of ASTM standards, soil and rock, West Conshohocken, PA: American Society for Testing and Materials. 
[41] ASTM D 1883-2016, "Standard test for California Bearing Ratio.: Annual book of ASTM standards, soil and rock, West Conshohocken, PA: American Society for Testing and Materials.

[42] ASTM D2166-2000, "Standard test method for unconfined compression test." Annual book of ASTM standards, soil and rock, West Conshohocken, PA: American Society for Testing and Materials.

[43] ASTM D2435-2004, “ Standard test method for consolidation test." Annual book of ASTM standards, soil and rock, West Conshohocken, PA: American Society for Testing and Materials.

[44] Kumar A., Walia B.S., Bajaaj A., "Influence of fly ash, lime and polyester fibers on compacted and strength properties of expansive soil", J. Mater.Civil Eng. Vol. 19, No. 3, 2007, pp. 242-248.

[45] Estabragh A.R., Ranjbari, S. and Javadi, A.A. "Properties of a Clay Soil and SoilCement Reinforced with Polypropylene Fibers". ACI, Mater. J., Vol. 114, No. 2, 2017, pp. 195-205.

[46] Kaya A. and Fang H.-Y., "The effects of organic fluida on physico chemical parameter of fine-grained soils", Can. Geotech. J., Vol. 37, 2000, pp. 943-950.

[47] Gouy G., "Sur la constitution de la charge electrique a la surface d'unelectrolyte", Anniue Phsique Parie, Vol. 9, No. 4, 1910, pp. 457-468.

[48] Chapman D.L., "A contribution to the theory of Electro-Capllarity", Philos. Mag, Vol. 25, No. 6,1913, pp. 475-481.

[49] Van Olphen H., "An introduction to clay colloid chemistry", Willey Interscience, New York, 1977. 
[50] Mohamed A.M.H. and Antia H.E., "Geoenvironmental Engineering", Elsevier, Amsterdam, the Netherlands, 1998.

[51] Tremblay H., Duchesne J., Locat J. and Leroueil S., "Influence of the nature of organic compounds on fire soil stabilization with cement." Can. Geotech. J., Vol.39, No.3,2002, pp. 535-546.

[52] Chartres C.J., Ringrose-Voase A.J. and Raupach M., “A comparison between acetone and dioxane and explanation of their role in water replacement in undisturbed soil samples”, J. Soil Sci., Vol.40, 1989, pp. 849-863. 


\section{List of tables}

Table. 1 Physico-chemical components of soil

Table.2 Atterberg limits and compaction parameters for natural and contaminated soil

Table. 3 Mechanical properties of natural soil and contaminated soil 
Table. 1 Physico-chemical components of soil

\begin{tabular}{|l|c|l|c|}
\hline $\begin{array}{l}\text { Chemical } \\
\text { component }\end{array}$ & Amount & $\begin{array}{l}\text { Chemical } \\
\text { component }\end{array}$ & Amount \\
\hline $\mathrm{pH}$ & 8.4 & $\mathrm{Mg}^{2+}($ meq/L) & 6.0 \\
\hline $\mathrm{EC}^{*}(\mathrm{dS} / \mathrm{m})$ & 13.90 & $\mathrm{Cl}^{-}($meq/L) & 49.0 \\
\hline $\mathrm{Na}^{+}(\mathrm{meq} / \mathrm{L})$ & 142.0 & $\mathrm{HCO}^{-}($meq/L) & 7.5 \\
\hline $\mathrm{Ca}^{2+}($ meq/L) & 21.0 & $\mathrm{SO}_{4}{ }^{2-}($ meq $/ \mathrm{L})$ & 112.0 \\
\hline
\end{tabular}

- Electrical Conductivity

Table.2 Atterberg limits and compaction parameters for natural and contaminated soil

\begin{tabular}{|c|c|c|c|c|c|}
\hline Materials & LL (\%) & PL (\%) & PI (\%) & $\begin{array}{c}\text { Optimum } \\
\text { water } \\
\text { content, } w \\
(\%)\end{array}$ & $\begin{array}{l}\text { Maximum } \\
\text { dry unit } \\
\text { weight, } \gamma_{d_{\max }} \\
\left(\mathrm{kN} / \mathrm{m}^{3}\right)\end{array}$ \\
\hline Soil & 80.0 & 26.0 & 54.0 & 20.0 & 16.5 \\
\hline $\begin{array}{c}\text { Soil+10\% } \\
\text { glycerol }\end{array}$ & 66.2 & 27.0 & 39.2 & 17.78 & 17.2 \\
\hline $\begin{array}{c}\text { Soil+15\% } \\
\text { glycerol }\end{array}$ & 42.0 & 20.0 & 22.0 & 11.23 & 17.6 \\
\hline $\begin{array}{c}\text { Soil+20\% } \\
\text { glycerol }\end{array}$ & 30.5 & 11.5 & 19.0 & 10.5 & 17.8 \\
\hline $\begin{array}{c}\text { Soil+10\% } \\
\text { acetone }\end{array}$ & 113.0 & 34.0 & 79.0 & 22.8 & 16.21 \\
\hline $\begin{array}{c}\text { Soil+15\% } \\
\text { acetone }\end{array}$ & 161.0 & 38.0 & 123.0 & 23.2 & 15.7 \\
\hline $\begin{array}{c}\text { Soil+20\% } \\
\text { acetone }\end{array}$ & 166.0 & 41.0 & 125.0 & 24.2 & 14.7 \\
\hline
\end{tabular}


Table. 3 Mechanical properties of natural soil and contaminated soil

\begin{tabular}{|c|c|c|c|c|c|c|}
\hline Materials & $\begin{array}{c}\text { Maximum } \\
\text { free } \\
\text { swelling } \\
(\%)\end{array}$ & $\begin{array}{c}\text { Unconfined } \\
\text { compressive } \\
\text { strength } \\
(\mathrm{kPa})\end{array}$ & $\begin{array}{c}\mathrm{CBR} \\
(\%)\end{array}$ & $\begin{array}{c}\text { Pre- } \\
\text { consolidatio } \\
\text { n pressure, } \\
P_{c}(\mathrm{kPa})\end{array}$ & $\begin{array}{c}\text { Compre } \\
\text { ssion } \\
\text { index, } \\
C_{c}\end{array}$ & $\begin{array}{c}\text { Swelli } \\
\text { ng } \\
\text { index, } \\
C_{s}\end{array}$ \\
\hline Soil & 20.6 & 475.0 & 6.57 & 45.0 & 0.7 & 0.02 \\
\hline $\begin{array}{c}\text { Soil+10\% } \\
\text { glycerol }\end{array}$ & 19.2 & 173.0 & 1.77 & 45.0 & 0.46 & 0.02 \\
\hline $\begin{array}{c}\text { Soil+15\% } \\
\text { glycerol }\end{array}$ & 1.38 & 68.13 & 1.39 & 45.0 & 0.46 & 0.02 \\
\hline $\begin{array}{c}\text { Soil+20\% } \\
\text { glycerol }\end{array}$ & 7.5 & 39.7 & 0.88 & 45.0 & 0.46 & 0.02 \\
\hline $\begin{array}{c}\text { Soil+10\% } \\
\text { acetone }\end{array}$ & 40.3 & 176.0 & 5.39 & 91.0 & 0.23 & 0.02 \\
\hline $\begin{array}{c}\text { Soil+15\% } \\
\text { acetone }\end{array}$ & 43.6 & 156.6 & 2.7 & 91.0 & 0.23 & 0.02 \\
\hline $\begin{array}{c}\text { Soil+20\% } \\
\text { acetone }\end{array}$ & 45.4 & 68.5 & 0.96 & 91.0 & 0.23 & 0.02 \\
\hline
\end{tabular}




\section{List of figures}

Fig.1. Compaction curves for natural soil and soil contaminated with different percentage of glycerol or acetone along with air voids lines

Fig.2. Variations of swelling (\%) with time for natural soil and soil contaminated with different percents of glycerol or acetone

Fig.3. Stress-strain curves for natural soil and soil contaminated with different percents of glycerol and acetone

Fig.4. CBR curves for natural soil and soil contaminated with different percents of glycerol or acetone.

Fig.5. Consolidation (loading-unloading) curves for natural soil and soil contaminated with different percents of glycerol

Fig.6. Consolidation (loading-unloading) curves for natural soil and soil contaminated with different percents of acetone

Fig.7. SEM images of a) natural soil, b) soil contaminated with glycerol, c) soil contaminated with acetone 


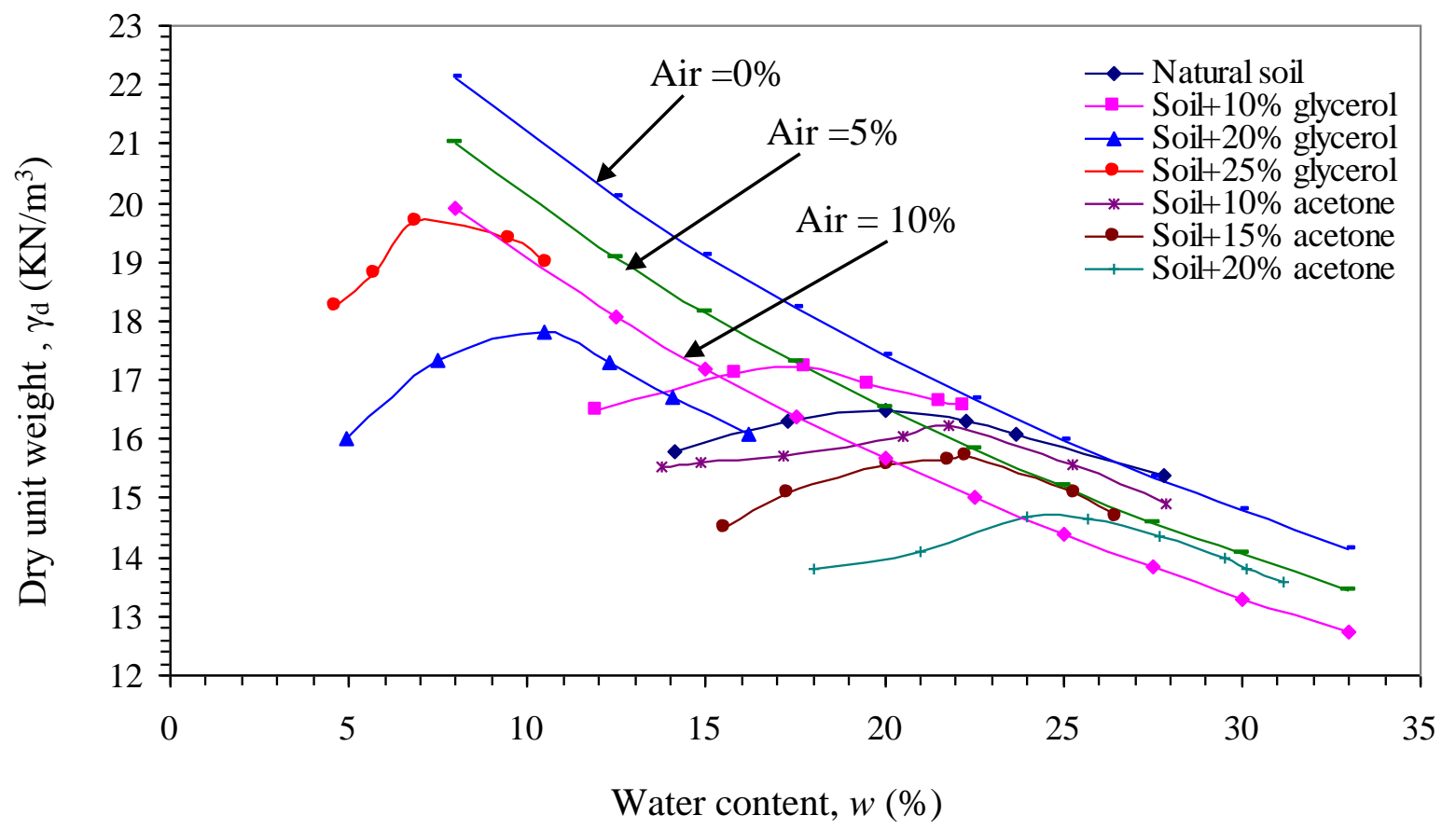

Fig.1. Compaction curves for natural soil and soil contaminated with different percentage of glycerol or acetone along with air voides lines 


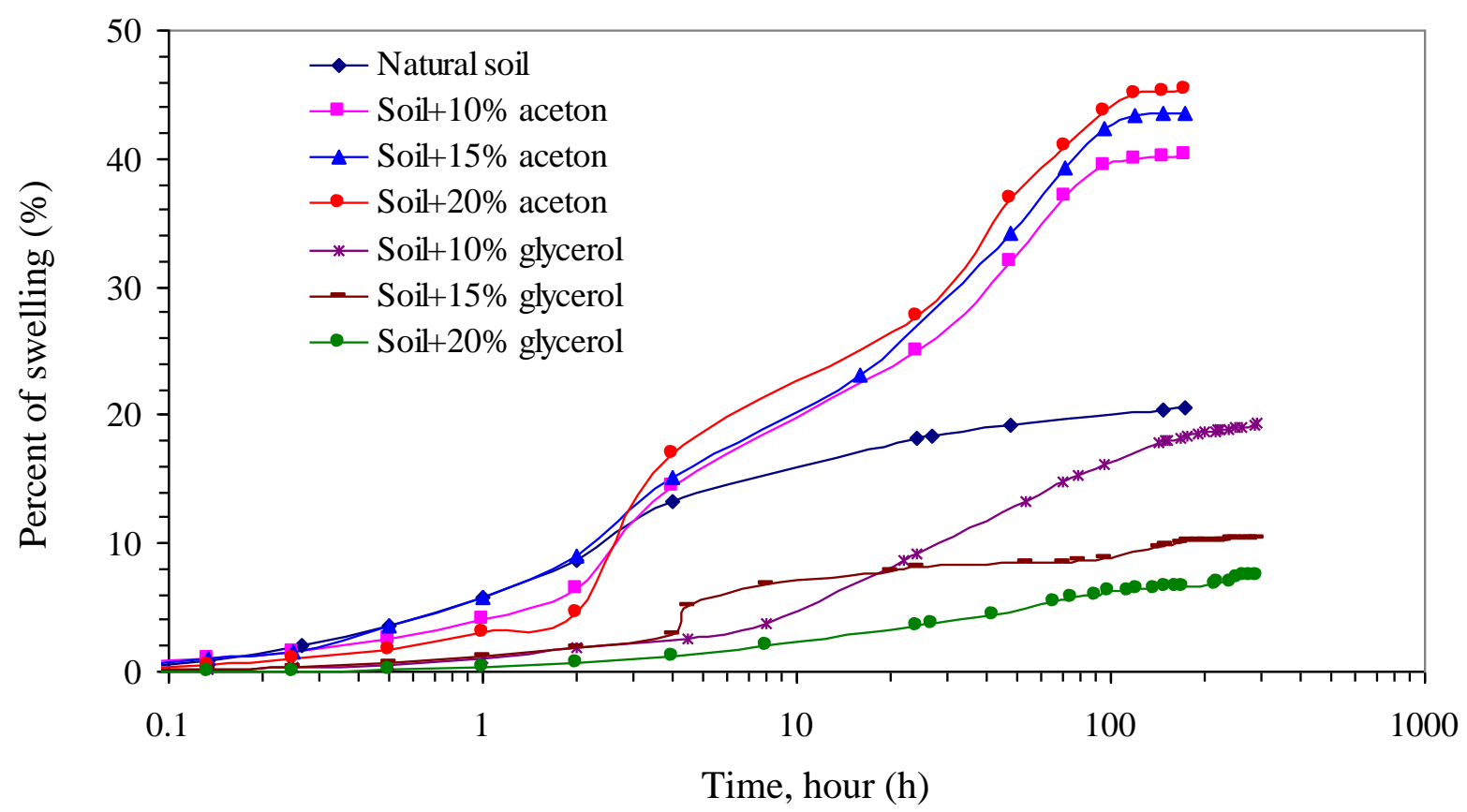

Fig.2. Variations of swelling (\%) with time for natural soil and soil contaminated with different percents of glycerol or acetone

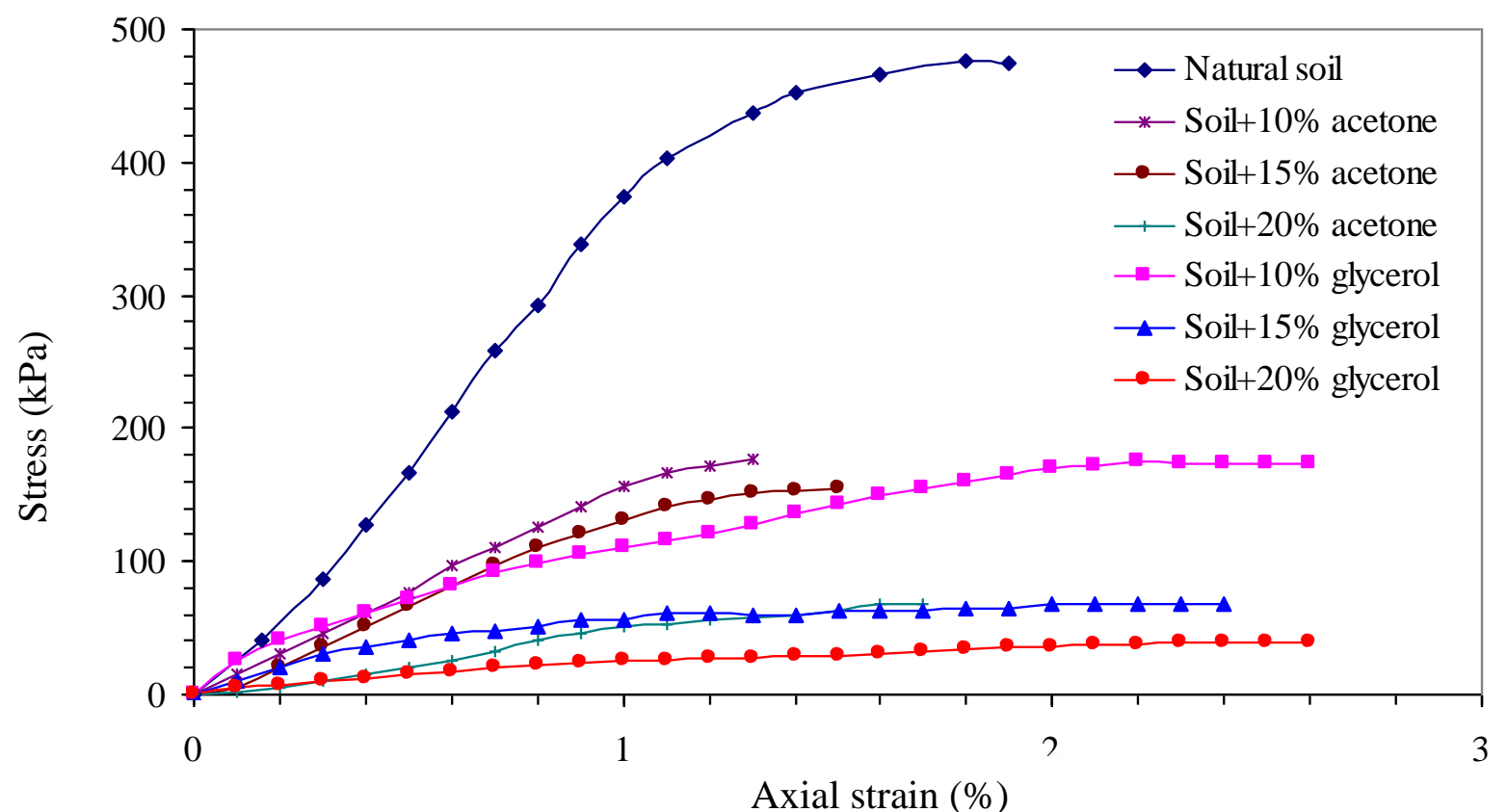

Fig.3. Stress-strain curves for natural soil and soil contaminated with different percents of glycerol and acetone 


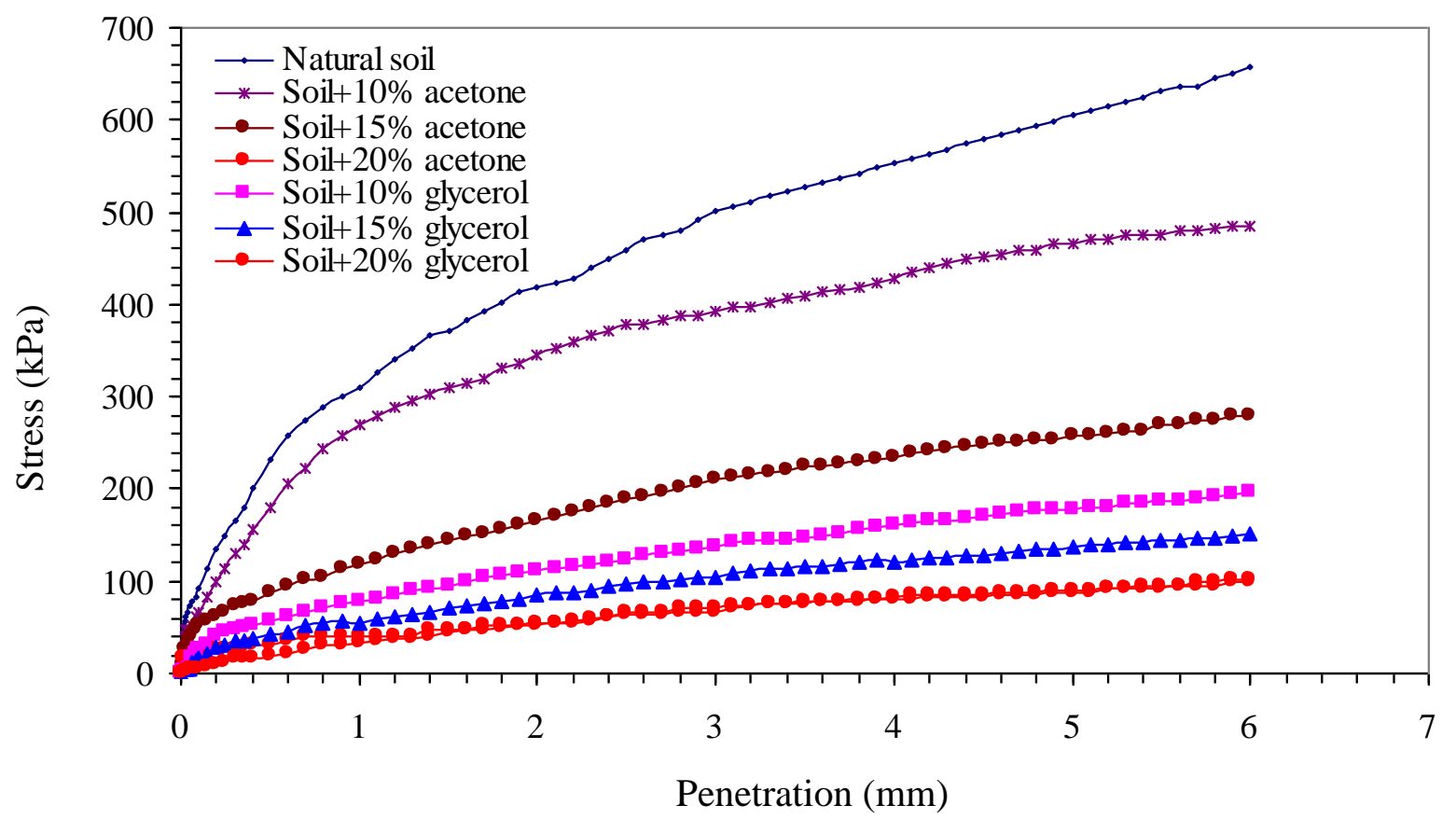

Fig.4. CBR curves for natural soil and soil contaminated with different percents of glycerol or acetone.

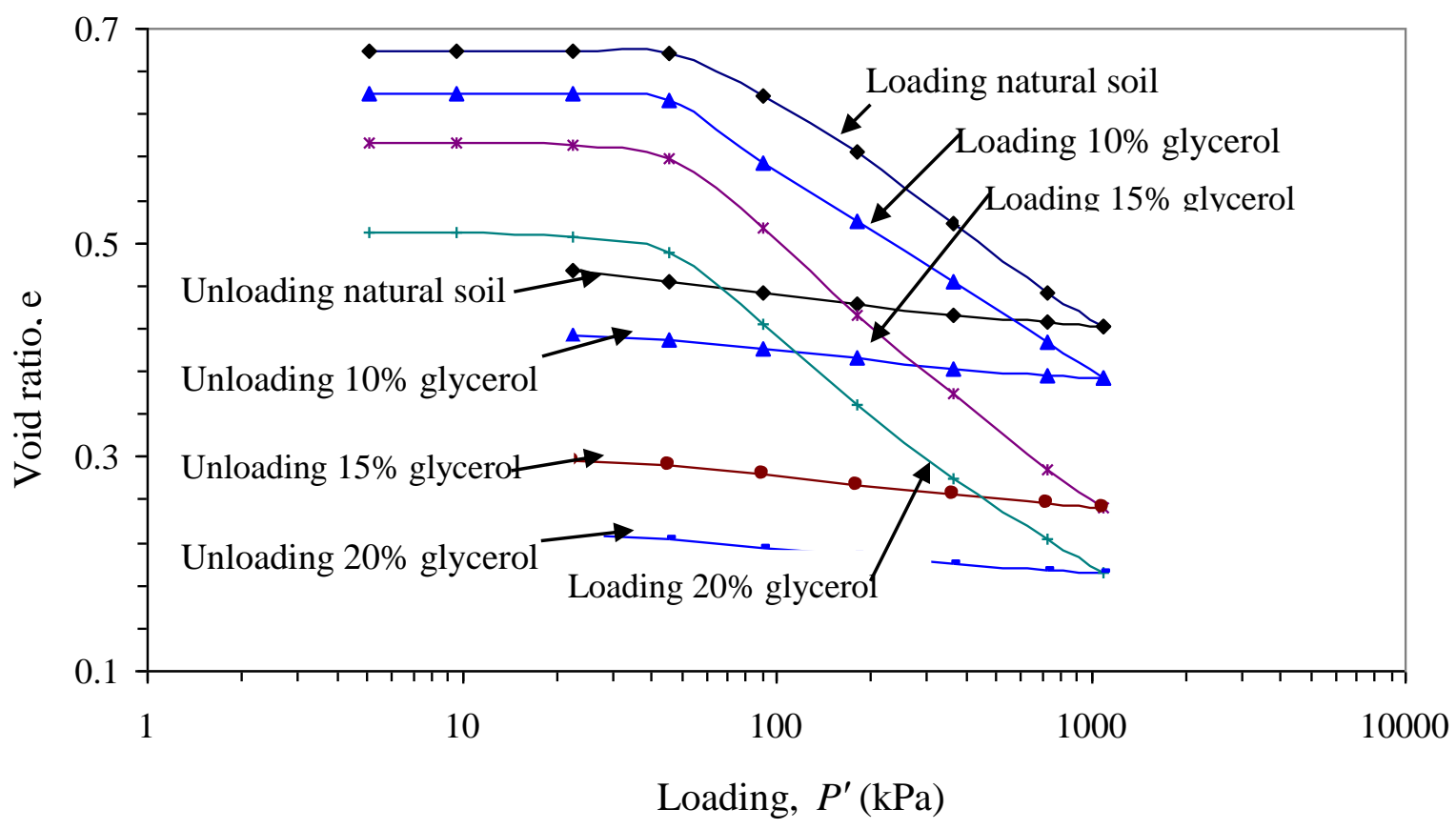

Fig.5. Consolidation (loading-unloading) curves for natural soil and soil contaminated with different percents of glycerol 


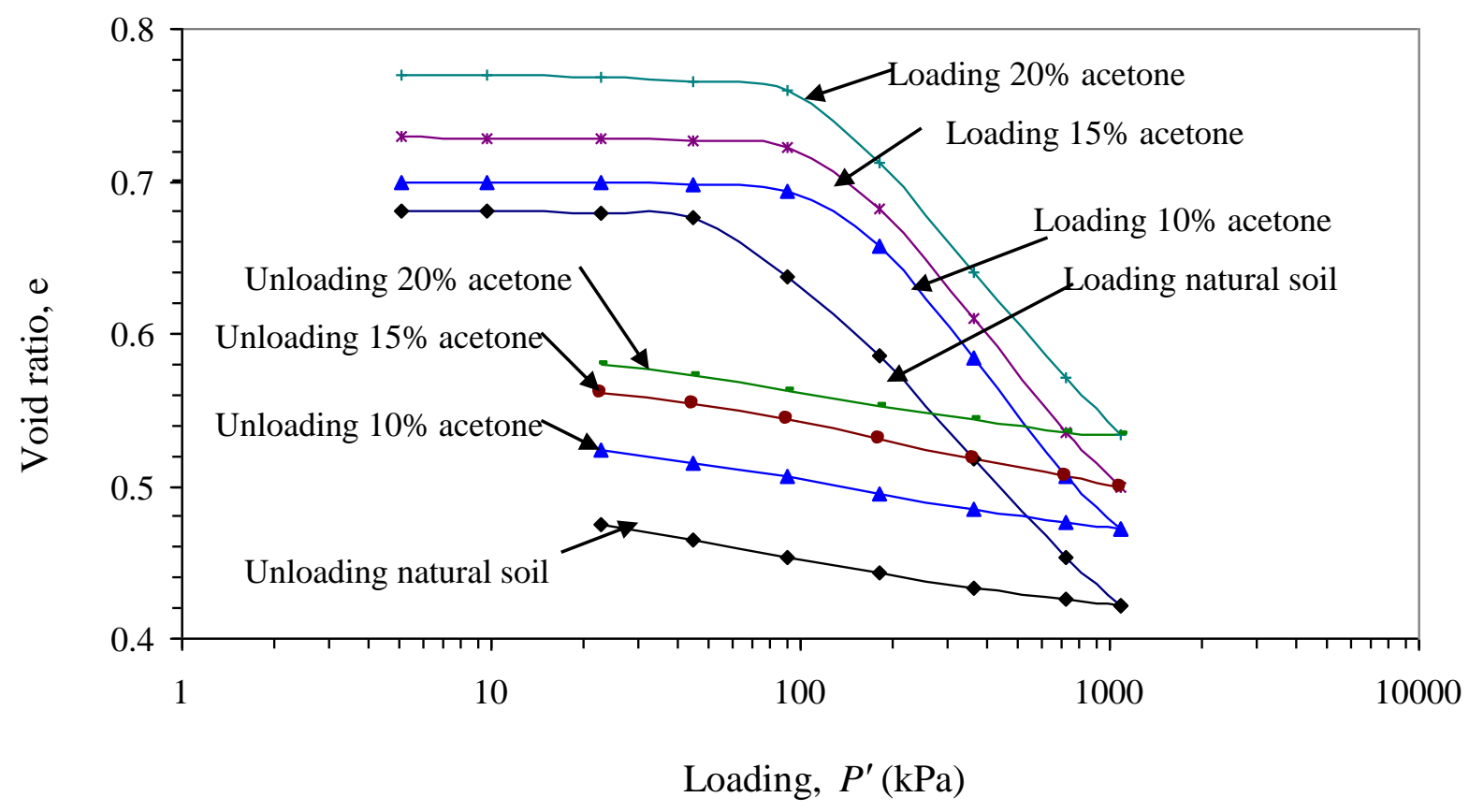

Fig.6. Consolidation (loading-unloading) curves for natural soil and soil contaminated with different percents of acetone 


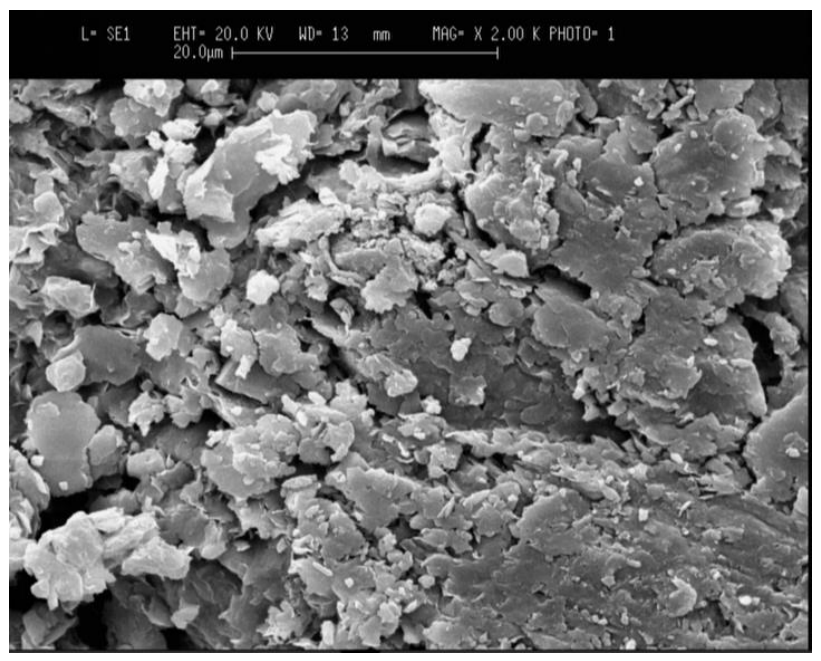

(a)

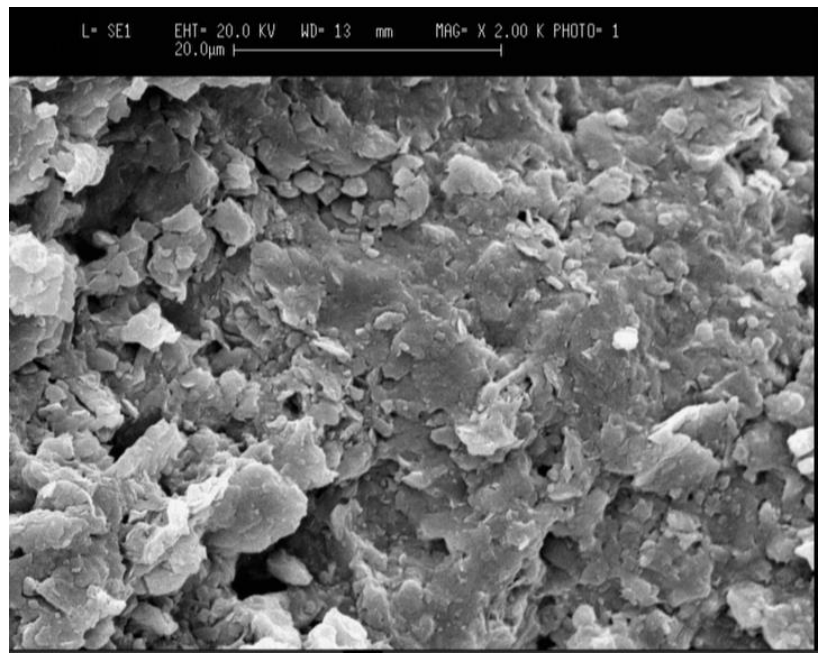

(b)

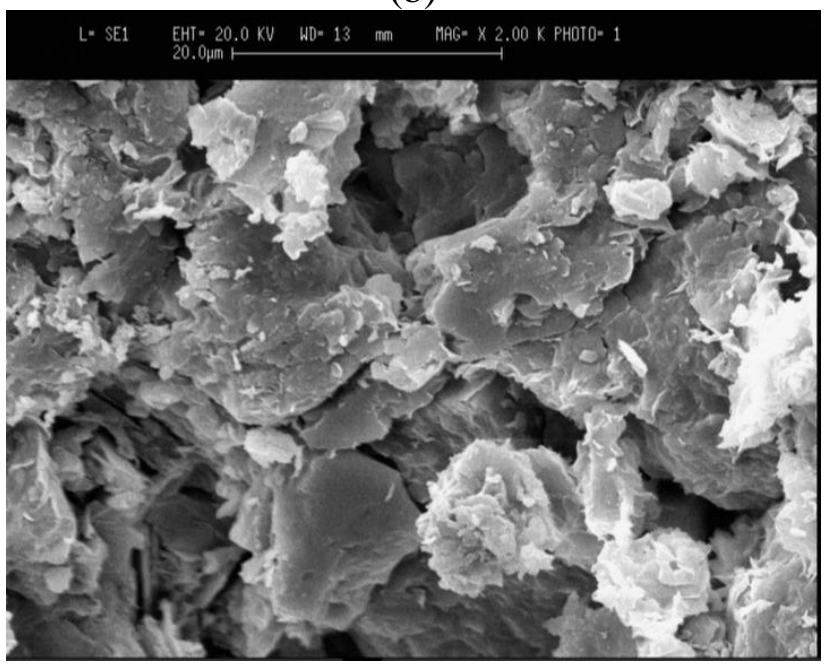

(c)

Fig.7. SEM images of a) natural soil, b) soil contaminated with glycerol, c) soil contaminated with acetone 